\title{
CAD intervention for Revival, Stylization \& Adaptation of Madhubani Traditional Textiles
}

\author{
YaminiJhanji Dhir
}

Department of Fashion \& Apparel Engineering, TIT\&S, Bhiwani, Haryana, India

To Cite this Article

YaminiJhanji Dhir, "CAD intervention for Revival, Stylization \& Adaptation of Madhubani Traditional Textiles", International Journal for Modern Trends in Science and Technology, 6(8S): 145-148, 2020.

\section{Article Info}

Received on 16-July-2020, Revised on 15-August-2020, Accepted on 25-August-2020, Published on 28-August-2020.

\section{ABSTRACT}

India is a country with rich culture and heritage which is reflected in the expression of folk art. Unity in diversity is apt not just in the dialect, lifestyle and cuisines of different states but also in the dress up and traditional art, craft and folk culture. Due to diversified talents, interests and inspiration, each state hasspecial identity for its unique folk painting. The art of madhubani painting is thetraditional style developed in the surrounding villages of madhubani in Mithila region,Bihar. The skill is handed down through generations, and hence the traditional designs \& patterns are widely maintained and being used in textiles as well. Apparel and accessory designers take inspiration from the lively, mythological and colorful motifs of this beautiful art form and have been extensively using these motifs for design and development of a gamut of high end artifacts, apparels, home textiles and accessories. Accordingly, designers have been working in close association with local artisans which can serve best of both worlds for artisans and designers alike. Moreover, the technological advancements in textile and fashion supply chain enables the designers to utilize CAD/CAM technologies utilizing time and resources more effectively to create hand sketches, virtual prototype samples digitally thus making best use of artesian skills along with latest technologies. Revival and promotion of this traditional textile craft by inclusion in latest apparel and accessory merchandise along with Computer aided designingcan go a long way in boosting this traditional folk art on national and international platform. As such, many designers are working in close association with local artisans, developing contemporary styles for modern era customers and even producing knock offs by digitization to cater to larger segment of consumers who wish to adorn the Madhubani apparels and accessories but wince due to exorbitant prices of authentic handcrafted pieces of workmanship.

KEYWORDS:Designers, CAD, Technology, Heritage, Madhubani, Folk, Culture, Apparels, Accessories.

\section{INTRODUCTION}

Madhubani painting is a traditional folk art of Bihar. Madhubani is synonym to Forest of Honey, a place near Durbhanga district in North Bihar. The places are well known for their beautiful traditional folk art- Madhubani painting.

The wall paintings are not merely an aesthetic entity but express much deeper connotations, themes and narratives in the form of stories that are narrated in a series of panels. Apart from their decorative purpose, the paintingsprovide an aid for visual education like picture books depicting the rich heritage of Bihar. The simplicity and connotations of the paintings leave the viewers spell bound and mesmerized at once.

Three traditional methods of paintings are prevalent among the folk artists:

- Wall-painting (bhittichitra) 
- Canvas-painting (patachitra)

- Floor-painting (aripana)

Among these the wall and the floor painting are the most popular art forms in Mithila region. The wall-paintings are referred to as Mural, Mithila or Madhubani paintings. The lovely canvas paintings painted in colored or black ink with figurative motifs depicting nature and mythology are not just fascinating but keep an individual close to his/her roots and traditions. Undoubtedly, the paintings have become an integral part of modern era's home decor for consumers having inclinations towards traditional textiles and art forms.

The art form isgenerally practiced by the women folk, though men arealso involved to explore it as a source of livelihood.

The wall paintings in rural set up areaccomplished on freshly plastered or a mud wall.However, the paintings are now being made on paper, canvas and cloth to be put for commercial usage $[1,2]$.

Madhubani paintings are practiced till date in the village of Jitwarpur, Ranti, Rasidpur, Bacchi, Rajangarh, etc. The art form is believed to date back to the times of the Ramayana when it is believed that King of Mithila, Janaka commissioned artisansto embellish their abode with these paintings on auspicious occasion of his daughter LordessSita to Lord Rama.

The locals and artisans in country side and nearby regions of Mithila have religious beliefs associated with the paintings and generallydecorate the pooja room, ritual area and bridal room, main village walls during processions, festivals, rituals and ceremonial activities.

The artisans have a strong belief that their art form which has passed down through several generations keep them connected to their Lords and is an emblematic expression of mundane experiences and beliefs.

Each symbols utilized in painting by Maithili painters has a specific meanings. Fish symbolize fertility, procreation and good luck, peacocks symbolizes love and religion, and serpents are indicative of divine protectors. Animal, human and several other forms are used in the paintings. Flora like lotus tree, bamboo forest, and fauna like fish, tiger, serpent, peacock and the mythological motifs of Gods, Goddesses are an integral part of wall, floor paintings $[3,4]$.

\section{ANIMAL FORMS:}

The paintings depict abundance of flaura and fauna motifs in natural phenomena as shown in Fig. 1(a) \& (b).
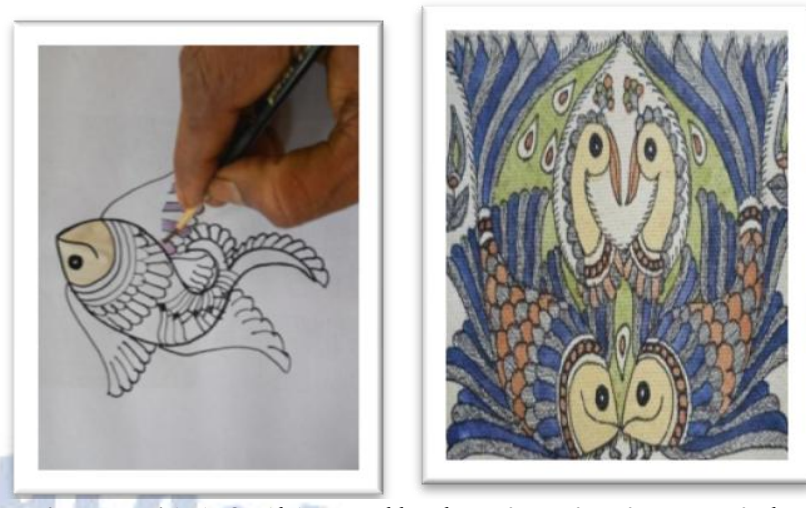

Figure 1(a) \& (b) Madhubani paintings with animal forms

\section{HUMAN FORMS}

Human forms are also frequently used in Madhubani paintings. The human figures

depict mythological characters, deities, various Gods and Goddesses such as Vishnu-Lakshmi, Shiva- Parvathi, Rama-Sita, Krishna-radhaetc as shown in Fig. 2(a) \& (b).

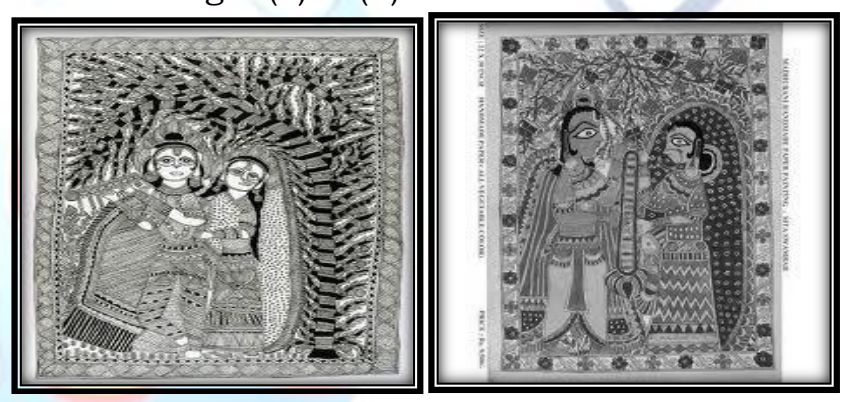

Figure 2 (a) \& (b) Madhubani paintings using human forms \& deities

\section{APPLICATION AREAS OF MADHUBANI PAINTINGS IN APPAREL \& ACCESSORY DESIGNING}

Apparel and accessory designers take inspiration from the lively, mythological and colorful motifs of this beautiful art form and have been extensively using these motifs for design and development of a gamut of high end artifacts, apparels, home textiles and accessories. Accordingly, designers have been working in close association with local artisans which can serve best of both worlds for artisans and designers alike. Revival and promotion of this traditional textile craft by incorporation in latest apparel and accessory merchandise can go a long way in boosting this traditional folk art on national and international platform [5]. The essence of art form can be seen in home textiles - bed linens, cushions and pillow covers and home décor articles. Furthermore, apparel and accessory range featuring the madhubani prints either hand printed or simulated using screen printing techniques are gaining wide spread acceptance among teenagers, young professionals and females 
alike. A range of apparels embellished with madhubani paintings like sarees, draperies- stoles, dupattas, kurtis, tops and accessories like umbrellas, footwear, handbags, jewellery, watches (Fig. 3 ) are taking the market by storm particularly craft mela, artisans markets, handicraft exhibitions etc.

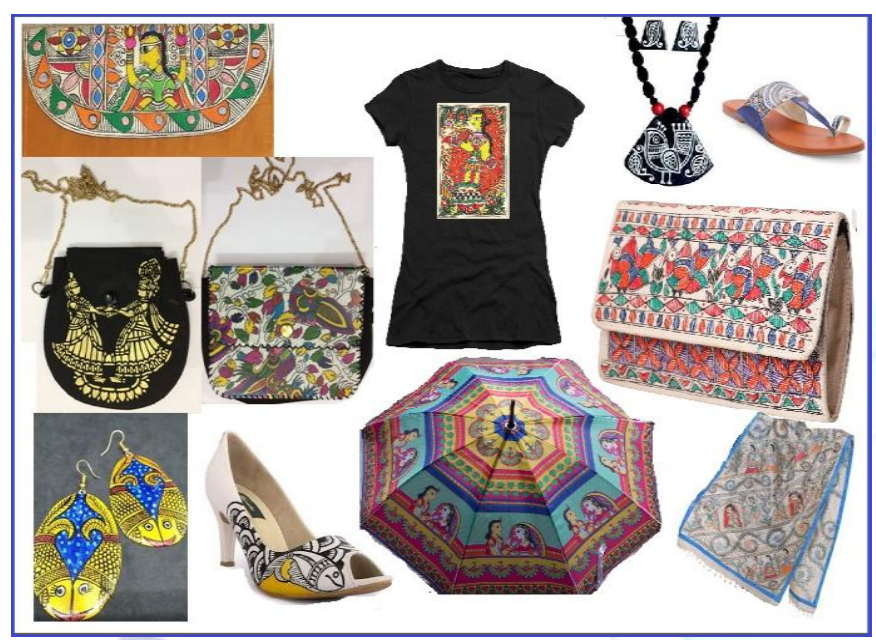

Fig. 3 Adaptation of Madhubani motifs in Apparels \& Accessories

\section{CAD INTERVENTION FOR DESIGN CREATION AND DIGITIZATION.}

The authentic, hand crafted Madhubani textiles are sold at exorbitant prices owing to intensive and intricate workmanship involved which may discourage middle income consumers to buy the merchandise inspite of their liking. Accordingly, designers and manufacturers ensure that this traditional textile art form doesn't remain confined to elite, up market consumers and fashion icons. Thus, the requirements of target mass consumers and fashion followers are fulfilled by designers via technological intervention, knock offs and switching over to digitalization and printed textiles taking inspiration from hand painted madhubani textiles. The hand painting on paper or fabric can be digitized and edited in software like Adobe Photoshop, Illustrator thus modifying the hand work and giving new dimensions to design elements. The PSD files can be imported to digital printers which can thus be digitally printed onto fabrics thereby reducing the time and cost considerably compared to conventional hand painting technique. The digitally printed fabrics can be utilized for creation of myriad of home décor and home textiles, draperies like stoles, dupattas and sarees, apparels and fashion accessories like handbags, belts, footwear etc. Thus, the consumers can buy digitally printed apparels and accessories embellished with madhubani motifs at much lower price points compared to hand painted ones. Fig. 4 shows some apparels and accessories designed from digitally printed madhubani fabrics. Although these lack the authenticity, workmanship of artisans and originality, but still are hot selling products as they serve as cheap knock offs of the original madhubani art forms.

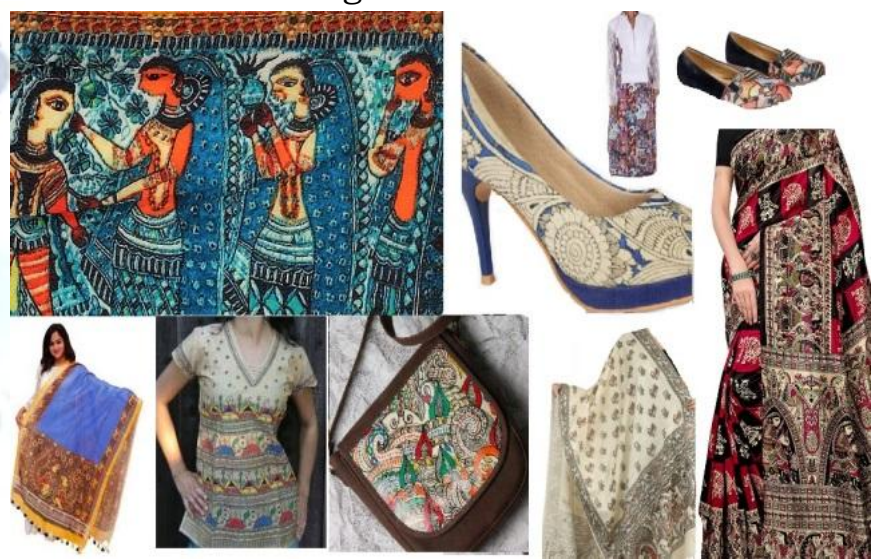

Fig. 4 - Digital printed Madhubani textiles used for apparels and accessories

\section{CONCLUSIONS}

Madhubani paintings are a blend of aesthetic appeal, rich Indian traditions and heritage. The collaborative approach of government, designers and manufacturers to promote the art form at a global platform can go a long way in generating non-agricultural income source of artisnas and encouraging them to pass on the legacy to future generations. Accordingly, designers are working in close association with artisan adapting the motifs and paintings in their apparel and accessory merchandise.Moreover, designers and manufacturers ensure that this traditional textile art form doesn't remain confined to elite, up market consumers and fashion icons. Thus, the requirements of target mass consumers and fashion followers are fulfilled by designers via technological intervention, creating cheaper versions - knock offs and switching over to digitalization and creation of printed textiles taking inspiration from hand painted madhubani textiles. The hand painting on paper or fabric can be digitized and edited in software like Adobe Photoshop, Illustrator thus modifying the hand work and giving new dimensions to design elements. The PSD files can be imported to digital printers which can thus be digitally printed onto fabrics thereby reducing the time and cost considerably compared to conventional hand painting technique. The digitally printed fabrics 
can be utilized for creation of myriad of home décor and home textiles, draperies like stoles, dupattas and sarees, apparels and fashion accessories like handbags, belts, footwear etc. Furthermore, The Government of India is supporting and encouraging the local artisans for promotion on this art form.

The fashion conscious and heritage loving Indians with an also play a pivotal role in revival and promotion of Indian traditional art forms like Madhubani and others.

\section{REFERENCES}

[1] http://www.mithilaart.com

[2] http://www.madhubanipaintings.com

[3] Takur,U. (1982) Madhubani Painting, Abhinava Publication, New Delhi.

[4] Dallapiccola, L. Indian Painting,The Lesser Known Traditions, Niyogi Books.

[5] Das, N. (2013, Feb 3)Madhubani paintings- its existence and possibility, International Journal of Scientific and Research Publications.
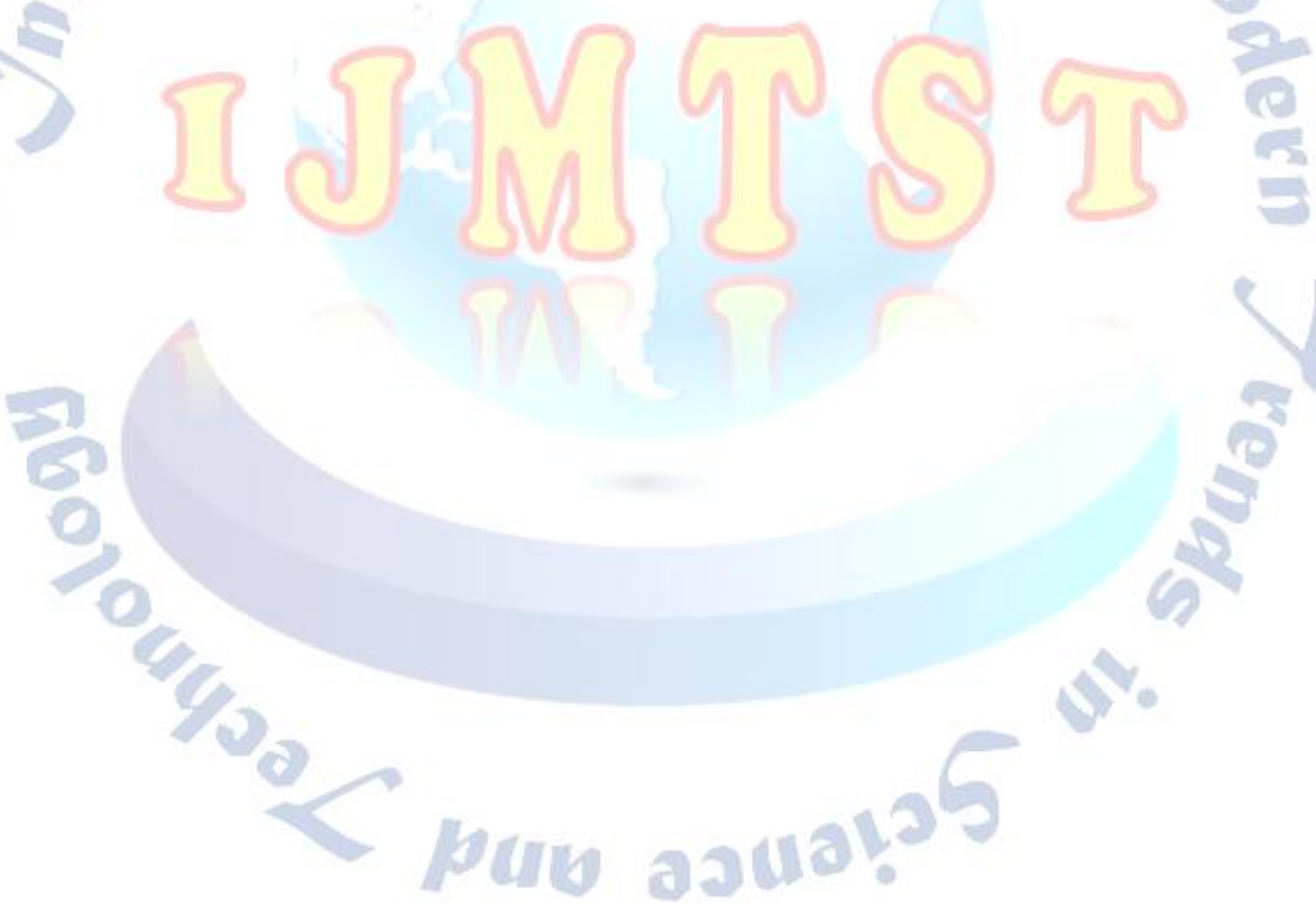